Check for updates

London, UK

Cite this as: $B M J$ 2021;372:n561 http://dx.doi.org/10.1136/bmi.n561 Published: 25 February 2021

\section{Covid-19: One in seven people in England have antibodies from infection or vaccination, finds study}

\author{
Jacqui Wise
}

Almost $14 \%$ of people in England now have evidence of antibodies against SARS-CoV-2, according to the fifth round of the Real-time assessment of community transmission (React-2) study. ${ }^{1}$

The study, led by Imperial College London, used the Fortress lateral flow test to detect antibodies in a drop of blood from the finger. Tests were sent to a random sample of the population between 26 January and 8 February 2021 and 154172 people in England had valid results. The study is published as a preprint and has not yet been peer reviewed. This round of the study included-for the first time-18 ooo people who had received at least one dose of a coronavirus vaccine.

Questionnaires completed by the study participants showed that overall vaccine confidence is very high with $92 \%$ saying that they had accepted, or intended to accept, the offer of a vaccine. However, confidence was lower among black people $(72.5 \%)$ than white people (92.6\%). Younger people were also more sceptical than older people. Particular concerns were identified around pregnancy, fertility, and allergies.

The snapshot survey found that the overall prevalence of antibodies was $13.9 \%$-up from 5.6\% in the previous round carried out between 27 October and 10 November last year and from $4.38 \%$ in September. The overall prevalence of antibodies in those who were vaccinated was $37.9 \%$ and $9.8 \%$ in unvaccinated people.

The study found an uneven distribution of SARS-CoV-2 antibodies in the population, with rates highest in London at $16.9 \%$. There was also a higher burden in key workers and some minority ethnic groups, similar to the pattern in the first wave.

The prevalence of antibodies in unvaccinated people was higher in people of black (22.4\%) and Asian (20.0\%) ethnicity compared to $8.5 \%$ in white people. Prevalence was highest among younger people and in those living in the most deprived communities.

Among unvaccinated people the highest prevalence of antibodies was found in care home workers at $24.2 \%$ and healthcare workers at $21.9 \%$. The survey also found that those in public facing jobs such as police officers and teachers were more likely to test positive (around 11\%) than non-key workers (7.8\%).

The researchers also analysed the antibody response in 12820 people who had received at least one dose of the Pfizer BioNTech vaccine more than 21 days previously. They found that two doses of vaccine, or a single dose following previous infection, confers high levels of antibody response across all age groups. Overall, $91 \%$ had antibodies after two doses of vaccine, rising to $95.5 \%$ in people under 60 . In those over 80 , the figure was slightly lower at $88 \%$.

The study also found a high proportion of people under 30 had antibodies after a single dose of vaccine, with $94.7 \%$ testing positive. However, the figure dropped steadily with age and in those over 80 the rate of positive results was $34 \cdot 7 \%$.

Paul Elliot, director of the React programme and chair in epidemiology and public health medicine at Imperial College London, told a Science Media Centre briefing, "Overall, regardless of age, we are seeing very high antibody positivity rates from two doses of the Pfizer vaccine and from one dose plus natural infection."

Helen Ward, professor of public health at Imperial, said there was a need for improved communication about perceived risks. "It is very encouraging to see that uptake and confidence in the vaccination programme is so high, and that most people develop a detectable antibody response after one dose. Our findings suggest that it is very important for people to take up the second dose when it is offered."

The latest results from the Office for National Statistics infection survey found that in recent weeks the number of people testing positive for covid-19 has decreased in both patient facing and non-patient facing job roles. ${ }^{2}$ This contrasts with January, which saw decreases only in the number of people in non-patient facing roles and reflects the overall decreasing infection rate seen across the UK. According to the survey, in England an estimated 1 in 115 people would test positive for covid-19 in the week ending 12 February. In Scotland the figure is 1 in 180 , in Wales 1 in 124, and in Northern Ireland 1 in 105 people would test positive for covid-19.

\section{Ward H, Cooke G, Whitaker M, et al. React-2 round 5: Increasing prevalence of SARS-CoV-2 antibodies demonstrate impact of the second wave and of vaccine roll-out in England. www.imperial.ac.uk/media/imperial-college/in- stitute-of-global-health-innovation/REACT-2-round-5-preprint.pdf. \\ 2 Office for National Statistics. Coronavirus (covid-19) infection survey, UK. 19 February 2021. www.ons.gov.uk/peoplepopulationandcommuni- ty/healthandsocialcare/conditionsanddiseases/bulletins/coronavirus- covid19infectionsurveypilot/19february2021.}

This article is made freely available for use in accordance with BMJ's website terms and conditions for the duration of the covid-19 pandemic or until otherwise determined by BMJ. You may use, download and print the article for any lawful, non-commercial purpose (including text and data mining) provided that all copyright notices and trade marks are retained. 